\title{
CIÊNCIA E TECNOLOGIA NOS MUNDOS IMAGINÁRIOS DE YANTOK: AVENTURAS DE KAXIMBOWN (1911-1913)
}

\author{
MARILDA LOPES PINHEIRO QUELUZ \\ Universidade TECNOLÓgica Federal do PARANÁ (UTFPR)
}

\begin{abstract}
RESUMO: O objetivo deste texto é refletir sobre as Aventuras de Kaximbown, de Max Yantok, publicadas na revista O Tico-Tico, entre 1911 e 1913. Nessas narrativas de nonsense e aventura, os personagens partem em viagens interplanetárias, descobrindo mundos imaginários, com seres fantásticos e outras formas de organização social, em espaços povoados de engenhosidades, máquinas mirabolantes e artefatos bizarros. O humor é construído pelos contrastes, pelo estranhamento e por uma crítica sutil às soluções técnico-científicas e às reformas urbanas. Yantok cria, graficamente, não lugares, entrelaçando elementos utópicos e distópicos, em uma paródia da modernização brasileira na Primeira República.
\end{abstract}

PALAVRAS-CHAVE: Yantok, Kaximbown, quadrinhos, tecnologia, cultura.

ABSTRACT: The purpose of this paper is to reflect upon the Adventures of Kaximbown, by Max Yantok, published in the journal O Tico-Tico between 1911 and 1913. In these narratives of nonsense and adventure, the characters embark on interplanetary travels, discovering imaginary worlds with fantastic beings and other forms of social organization, in areas populated with ingenuities, fancy machines, and bizarre artifacts. Humor is built by the contrasts, the strangeness, and a subtle critique to the technical-scientific solutions and the urban reforms. Yantok graphically creates non-places, intertwining utopian and dystopian elements in a parody of Brazilian modernization in the First Republic.

KEYWORDS: Yantok, Kaximbown, comics, technology, culture. 


\section{Introdução}

Esse texto pretende refletir sobre as representações de ciência e tecnologia em Aventuras de Kaximbown, uma história em quadrinhos criada por Max Yantok, publicada na revista infanto-juvenil, $O$ Tico-Tico. O recorte temporal é o período de 1911 (quando as aventuras iniciam) a 1913 (quando todos os personagens morrem). ${ }^{1}$

O caricaturista Max Yantok (1881-1964)² atuou em várias áreas: foi engenheiro agrimensor e contador e desempenhou funções como projetos de arquitetura, medição de terrenos, além de, eventualmente, tocar violino em orquestras. Desenhou para revistas como O Malho (1902-1954), Fon-Fon (1907-1958), Revista da Semana (1900-1959), entre outras.

Segundo Herman Lima ${ }^{3}$, o entusiasmo do desenhista pelas invenções era tal, que teria chegado a patentear algumas. Interagindo com sua época, Yantok procurou, simultaneamente, desenvolver novas técnicas e criar representações gráficas sobre a realidade, auxiliando a constituição de uma cartografia das técnicas, simbólica e material, das primeiras décadas do século XX.

Antes de analisar os quadrinhos de Yantok é preciso estabelecer que consideramos ciência e tecnologia como construções sociais situadas em determinado tempo e espaço. Costuma-se associar a complexidade técnicocientífica aos artefatos, mais especificamente às máquinas, naturalizando e tornando invisíveis os sistemas de organização social e econômica ligados a elas. Discutir tecnologias é evidenciar a agência humana, é pensar nas relações de trabalho, nos processos de mediação, de apropriação e de interpretação dos artefatos. É compreender que "as máquinas, assim como os sistemas tecnológicos" ${ }^{\prime 4}$ interferem e sofrem interferência dos diversos grupos sociais que atuam nas práticas rotineiras de usos deles.

David Nye ${ }^{5}$ ressalta que as tecnologias são também os diversos modos de percepção de mundo, que geram narrativas tecnológicas para dar sentido às mudanças cotidianas que vêm junto com a adoção de novas máquinas. Essas narrativas tecnológicas interpelam o imaginário do período, rearticulando, simbolicamente, as transformações sociais.

\footnotetext{
${ }^{1} \mathrm{O}$ personagem Kaximbown e seu grupo reapareceram nos anos seguintes e em outras fases da revista, mas com outras características e enfoques.

2 De acordo com Herman Lima, Max Yantok nasceu no Rio Grande do Sul "[...] numa data incerta, que o caricaturista supõe tenha sido 1881" (LIMA, Herman. História da caricatura no Brasil. Rio de Janeiro: J. Olympio, 1963, v. 3, p. 1.252). Há indícios de que o ano seria 1879 . 0 verdadeiro nome de Max Yantok seria Nicolau Cesarino, embora fosse conhecido como Max Cesarino Yantok. Era filho do imigrante italiano João Cesarino e da filha de um pajé de uma tribo indígena tupi, "cujo nome arrevesado o italiano transformou em Maurícia" (LIMA, op. cit., p. 1.251). Luchetti aponta controvérsias também em torno da data de morte do caricaturista, sendo a mais aceita a do ano de 1964, ainda que haja referência a 1965. (LUCHETTI, Marco Aurélio. Os grandes artistas de $O$ Tico-Tico em Vergueiro, W. Y Santos, R.E. (org.) O Tico-Tico: centenário da primeira revista de quadrinhos do Brasil. São Paulo: Opera Graphica, 2005, p. 66). Yantok usava pseudônimos como Mefisto, Ketno, W. Ketno, e Vladir Ketno.

${ }^{3}$ LIMA, Herman. História da caricatura no Brasil. Rio de Janeiro: J. Olympio, 1963, v. 3.

${ }^{4}$ NYE, David E. Narratives and Spaces: Technology and the Construction of American Culture, New York: Cambridge University Press, 1998, p. 5.

${ }^{5}$ NYE, David. Op. cit., p. 3.
} 
Javier Lorca exemplifica esse processo ao considerar que há um vínculo entre as inovações tecnológicas e o gênero de ficção científica, como diferentes construções discursivas, em uma estreita imbricação, de modo não determinista. "Es decir, que los imaginarios hegemônicos trascienden diversos campos de la cultura y que producción literaria y formación social se vinculan por un sistema de lazos y correspondencias". ${ }^{6}$ Nas reflexões sobre o humor gráfico, parece-nos "[...] essencial procurar sob que formas múltiplas se exprime um imaginário social traduzindo certo dinamismo e uma vontade de transformação global da realidade existente"."

Tanto as charges quanto os quadrinhos de Yantok refletem e refratam ${ }^{8}$ as transformações sociotécnicas ocorridas no Brasil das primeiras décadas do século $X X$.

\section{O contexto republicano e as Aventuras de Kaximbown}

O início da República brasileira caracterizou-se por uma modernização conservadora, pautada nas reformas das cidades e nas inovações técnicas. 0 medo e o encantamento pelas máquinas, em como a reapropriação dos artefatos e dos espaços públicos, implicaram uma constante negociação de significados da experiência urbana, das novas percepções do entorno e do tempo. A maioria da população alimentava a suspeita de que os "milagres" do progresso e as novas invenções não eram suficientes para transformar a política ou melhorar a condição social. ${ }^{9}$

A capital, Rio de Janeiro, inspirava-se nas grandes metrópoles europeias e apresentava-se como vitrina de civilidade, anunciando oportunidades de trabalho e de mercado, embora excluísse muitos setores sociais em nome da modernidade e da racionalidade, especialmente a população negra e pobre. Vigoravam modelos deterministas de interpretação social, teorias que defendiam hierarquias entre as raças, usando a ciência e a biologia para explicar os diferentes acessos à cidadania e a desigualdade entre brancos e negros. ${ }^{10}$

\footnotetext{
${ }^{6}$ LORCA, Javier. Historia de la ciencia ficción y sus relaciones com las máquinas (de las naves espaciales a los cyborgs). Buenos Aires: Capital Intelectual, 2010, p. 14.

7 TROUSSON, Raymond. Utopia e utopismo. In MORUS. Utopia e renascimento. Dossiê: Utopia como gênero literário. Campinas, SP, Unicamp, n. 2, p. 128, 2005.

${ }^{8}$ Refletir e refratar, no sentido bakhtiniano de que, considerando as múltiplas experiências concretas e cotidianas das pessoas, os signos não apenas descrevem a realidade e o mundo, mas constroem diversas interpretações sobre eles. BAKHTIN, M. \& VOLOCHINOV, V. N. Marxismo e filosofia da linguagem. São Paulo: Annablume; Hucitec, 2002.

${ }^{9}$ Ver SEVCENKO, Nicolau. A capital irradiante: técnica, ritmos e ritos do Rio. In: História da vida privada no Brasil : 3 (República da Belle époque à Era do Rádio). São Paulo: Cia. das Letras, 1998 , p. 513-619.

${ }^{10}$ Ver SCHWARCZ, Lilia Moritz (org.) A abertura para o mundo: 1889-1930. História do Brasil Nação 1808-2010, volume 3. Rio de Janeiro: Objetiva, 2012.
} 
Sem mudar as estruturas de um sistema patriarcal e oligárquico, o regime republicano apostou nos ideais burgueses de civilização e modernidade. Sonhava-se com um progresso constante e linear, aguçando a imaginação para um futuro em que a ciência e a técnica seriam responsáveis por reduzir as incertezas e as assimetrias sociais, por meio de um total domínio sobre a natureza e a humanidade.

A imprensa incrementava suas técnicas e processos gráficos e os periódicos ilustrados ganhavam espaço com o aprimoramento da qualidade das imagens. Nesse contexto, foi lançada, em 1905, no Rio de Janeiro, a revista $O$ Tico-Tico, anunciada como um "Jornal das Crianças". Trazia em suas páginas histórias em quadrinhos, jogos, contos, poesias, romances de aventuras ilustrados, sendo a revista com o maior tempo de publicação na história brasileira. ${ }^{11}$

Max Yantok teve uma longa participação na revista $O$ Tico-Tico, criando personagens como Kaximbown, Pipoca e Pistolão, o Barão de Rapapé, João Miséria, Pandareco, Parachoque e Viralata, entre outros. Escreveu e ilustrou alguns contos e foi o autor de vários títulos da Biblioteca Infantil de O Tico-Tico.

Nos traços quase surrealistas das histórias de Kaximbown, observa-se, além da influência de Winsor McCay $(1869-1934)^{12}$, um intenso diálogo, ainda que atravessado pelo deboche e por uma ironia nonsense, com a obra de Júlio Verne $(1828-1905)^{13}$. Em sua juventude, Yantok teria conhecido

o famoso escritor, que estava ao portão, tratando modestamente de suas flores, parecendo-lhe, antes, um jardineiro. Levados ao gabinete do prodigioso visionário do futuro, o caricaturista brasileiro não pôde deixar de surpreender-se com a desordem da sala, onde havia livros empilhados até o chão. Júlio Verne declarou aos visitantes, francamente, que detestava viagens, nunca saía de seu

\footnotetext{
${ }^{11}$ Mais informações em VERGUEIRO, Waldomiro \& Santos, Roberto Elísio dos. (org.) O TicoTico: centenário da primeira revista de quadrinhos do Brasil. São Paulo: Opera Graphica, 2005.

12 Para Roberto Elísio dos Santos, Yantok seguiu a "linha de Little Nemo" para criar as aventuras de Kaximbown. Em 1905 saiu a primeira página dominical de Little Nemo in Slumberland, a mais conhecida criação de Winsor McCay, um universo de sonhos que lidava com o inconsciente de um personagem, em paisagens fantásticas e um desenho impecável e criativo que transformou a linguagem dos quadrinhos. McCay também foi um dos pioneiros na arte da animação. SANTOS, Roberto Elísio. Artistas e personagens de destaque na revista $O$ Tico-Tico em Vergueiro, W. \& SANTOS, R.E. (org.). O Tico-Tico: centenário da primeira revista de quadrinhos do Brasil. São Paulo: Opera Graphica, 2005, p. 89-95. Ver também GOIDANICH, Hiron Cardoso y KLEINERT, André, Enciclopédia dos quadrinhos. Porto Alegre, RS: L\&PM, 2011, p. 311.

${ }^{13}$ Para Gregory Claeys, Verne foi o autor especulativo francês de ficção científica mais famoso de sua época e um pioneiro do gênero. "[...] De modo geral, otimista com a capacidade da humanidade de utilizar tecnologia para dominar a natureza, escreveu dezenas de romances e contos com temas científicos, moldando-os para acompanhar os desenvolvimentos científicos. Verne simboliza a obsessão por maquinário e inovação tecnológica que dominou sua época. Suas obras mais conhecidas são Viagem ao centro da terra (1863), Cinco semanas em um balão (1863), Da Terra à Lua (1865), Vinte mil léguas submarinas (1870) e $A$ volta ao mundo em oitenta dias (1873)." CLAEYS, Gregory. Utopia. A história de uma ideia. São Paulo: Edições Sesc-SP, 2013, p. 167.
} 
gabinete, indo raramente a Paris e isso mesmo para tratar de negócios com seu editor [...]. Em lembrança dessa visita, muitos anos depois, Yantok publicava seu livro de aventuras, Phil Hardigan, uma continuação das Vinte mil léguas submarinas, o que ele imagina ser muita pretensão sua. ${ }^{14}$

De acordo com Gregory Claeys, o uso utópico da ciência do final do século XIX provocou um fascínio maior por máquinas, principalmente as utilizadas em viagens, explorações e guerras. Nesse sentido, as obras de Júlio Verne foram muito influentes, pois uniram "dois importantes temas utópicos: a viagem épica e o uso de inovação tecnológica para avançar as fronteiras do conhecimento humano. No fundo dos oceanos, na atmosfera, muito além da Terra, seus heróis trabalhavam incansavelmente para subjugar a natureza em prol da humanidade."15

As representações de progresso no século XIX e início do XX estavam associadas não só às invenções e inovações técnicas, mas, também, eram fortemente ligadas à ideia da expansão imperial europeia. ${ }^{16}$

Temperadas de humor, ironia, nonsense e aventura, as histórias de Kaximbown e seu pequeno grupo narram viagens interplanetárias, em busca do desconhecido, descobrindo mundos imaginários, com seres fantásticos e animais fabulosos, e outras formas de organização social, em lugares povoados de estranhas engenhosidades, máquinas mirabolantes e artefatos bizarros.

Para Octavio Aragão Júnior, "Longe de buscar a acuidade científica, Yantok estruturava suas aventuras sobre a mais desabrida fantasia, sempre com um pequeno enfoque satírico e contemporâneo, mas, como visava ao público infantil, as críticas não eram tão ferinas."${ }^{17}$ Entretanto, no desenrolar da ficção científica de Yantok, encontram-se muitas cenas violentas e uma insistente crítica aos perigosos usos da ciência e da tecnologia, à imprensa, aos métodos de ensino, sugerindo associações com o que acontecia naquela conjuntura brasileira.

As aventuras de Kaximbown iniciam em Fantasiópolis, passando pelo Polo Norte e pela Pandegolândia, terminando tragicamente no Planeta Marte.

\footnotetext{
${ }^{14}$ LIMA, Herman. História da caricatura no Brasil. Rio de Janeiro: J. Olympio, 1963, v. 3, p. 1.255.

${ }^{15}$ CLAEYS, Gregory. Utopia. A história de uma ideia. São Paulo: Edições Sesc-SP, 2013, p. 156.

${ }^{16}$ Op. cit., p. 158.

${ }^{17}$ ARAGÃO JÚNIOR. Octavio. Visões do pretérito: a ficção científica nos quadrinhos brasileiros no século 20. In: ga Arte, São Paulo, vol. 1, n. 1, 67-76, $1^{\circ}$ Semestre, 2012.
} 


\section{Fantasiópolis}

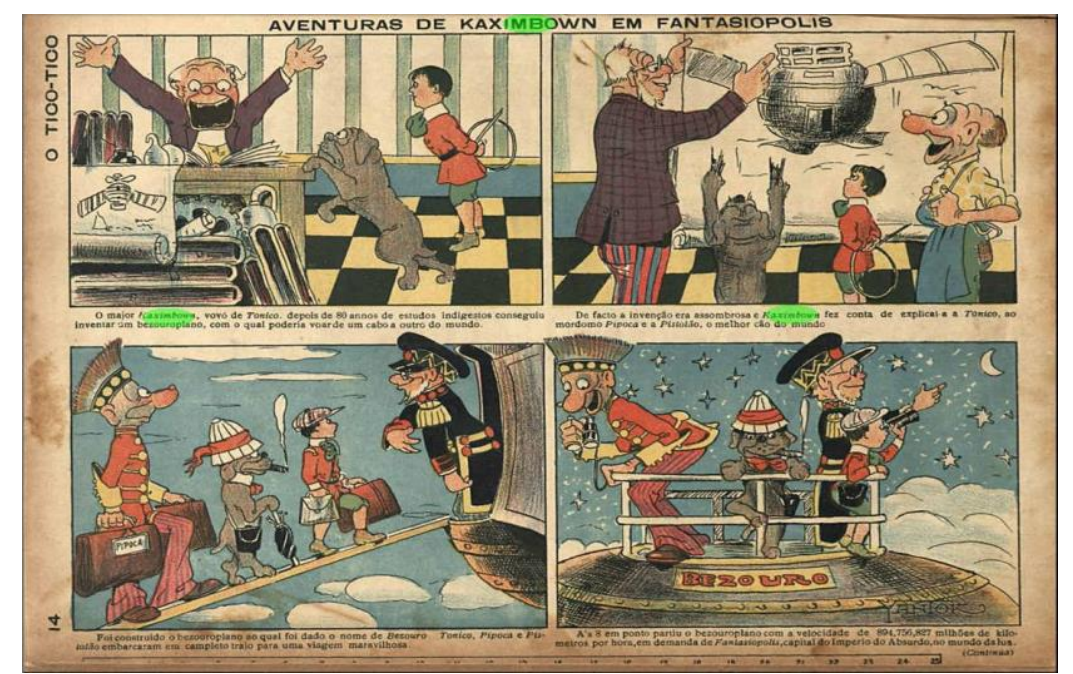

Figura 1. "Aventuras de Kaximbown em Fantasiópolis" (Yantok. O Tico-Tico, n. 303, p. 14, 26/7/1911). Acervo Hemeroteca Digital da Biblioteca Nacional.

No primeiro episódio das Aventuras de Kaximbown em Fantasiópolis (Figura 1), constatamos a emoção na gestualidade corporal dos braços abertos e da boca escancarada do "major Kaximbown" que "depois de 80 anos de estudos indigestos conseguiu inventar um besouroplano, com o qual poderia voar de um cabo a outro do mundo". O primeiro quadrinho mostra o ambiente das pesquisas, com muitos livros, desenhos, uma engrenagem, elementos de laboratórios de química. Na composição da cena, na felicidade da descoberta, acompanhada pelos olhos curiosos do neto Tonico e do cão, explicita-se a ideia do gênio maluco, excêntrico, sugerindo-se a tecnologia como fruto da invenção individual. ${ }^{18}$ No segundo quadrinho, vemos, junto com Tonico, o mordomo, Pipoca e Pistolão - "melhor cão do mundo" -, o desenho frontal do "besouroplano", basicamente uma esfera com asas. O mordomo, admirado, aparece com um avental e uma calça remendada, marcando a diferença de classe. Aliás, ao longo da viagem, ficamos sabendo que ele é analfabeto.

É interessante observar os trajes usados no momento da partida, em que os aventureiros sobem a rampa para entrar na estranha nave. Pipoca encontrase por último, com uma espécie de farda, e algo que lembra um cocar à cabeça, carregando duas grandes malas. Pistolão está caracterizado como um soldado britânico. Tonico acrescenta ao visual um boné. Kaximbown está fardado, com quepe, no comando do grupo. Yantok trabalha com os estereótipos presentes no imaginário social sobre a figura do explorador, ou seja, geralmente vista como de caráter militar e imperialista. Tal estereotipia é ironizada, imageticamente, ao ser amalgamada à figura do explorador por excelência, o indígena. No último quadrinho, munidos de binóculo e luneta para

\footnotetext{
${ }^{18}$ Para uma crítica a esta visão, característica do período estudado, ver: EDGERTON, David. De La Innovacion Al Uso: Diez Tesis Eclécticas Sobre La Historiografía De Las Técnicas. In: Quaderns D'historia De L'enginyeria, v. VI, 2004.
} 
observar o universo, partem a uma velocidade de "894.756.827 milhões de quilômetros por hora", para Fantasiópolis, capital do Império do Absurdo, no mundo da Lua.

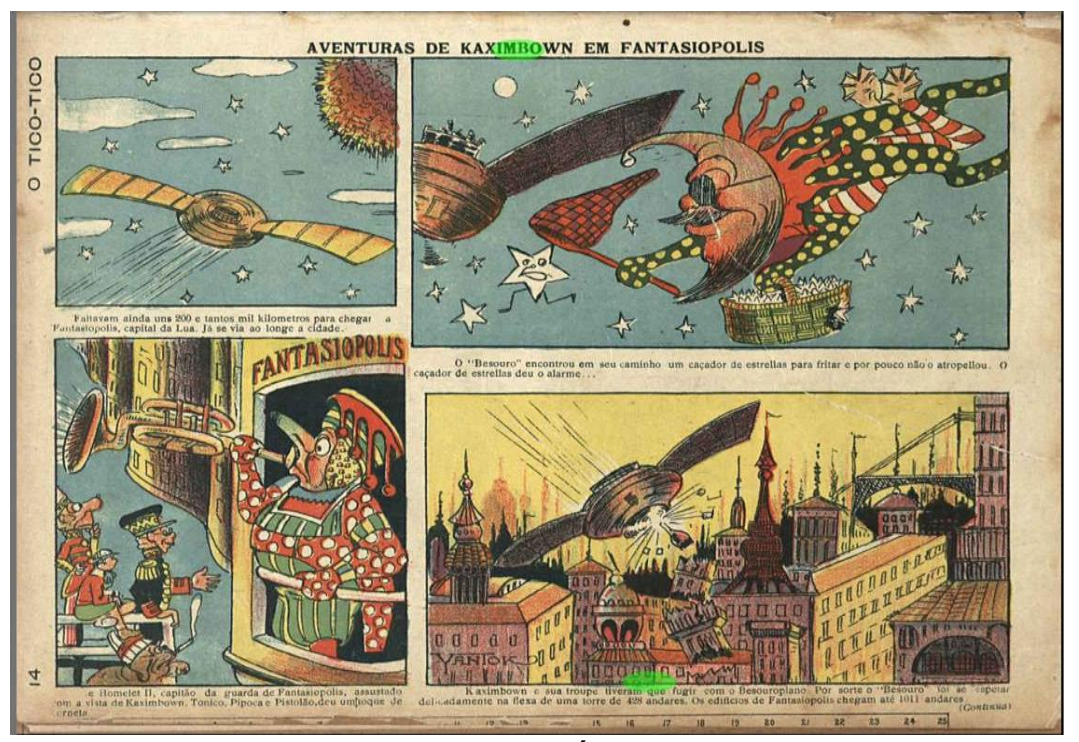

Figura 2. "Aventuras de Kaximbown em Fantasiópolis" (Yantok. O Tico Tico, n. 304, p. 14, 2/8/1911). Acervo Hemeroteca Digital da Biblioteca Nacional.

Na sequência (Figura 2), nota-se um maior dinamismo da página com dois formatos de quadrinhos, linhas de ação para o movimento da nave, perspectiva acentuada e predomínio das linhas diagonais. Os habitantes de outros mundos, em geral, são seres fantásticos, híbridos ou oníricos, como o "caçador de estrelas para fritar", com rosto de meia lua e vestes de bufão; Homelet II, capitão da guarda de Fantasiópolis, uma brincadeira com a sonoridade do nome do personagem de Shakespeare, tocando corneta, com roupa colorida, bolinhas, listras e chapéu de menestrel; "Watapah, cônsul do Império da Ilusão"19, uma espécie de monstro verde, cujo nome lembra o vatapá, prato típico da culinária baiana.

Como a maioria das cidades imaginadas por Yantok, destaca-se a arquitetura eclética, com arcos e cúpulas convivendo com linhas retas modernistas, com prédios de torres de $428,1.011$ ou 1.318 andares, de acordo com o texto, além de pináculos. Em outros momentos, a arquitetura sofisticada e com toques orientais é caracterizada pela modernização, em exemplos como as escadas substituídas por calçadas movediças, com esteiras rolantes (Figura 3).

${ }^{19}$ O Tico-Tico, n. 305, 9/8/1911, p. 14. 


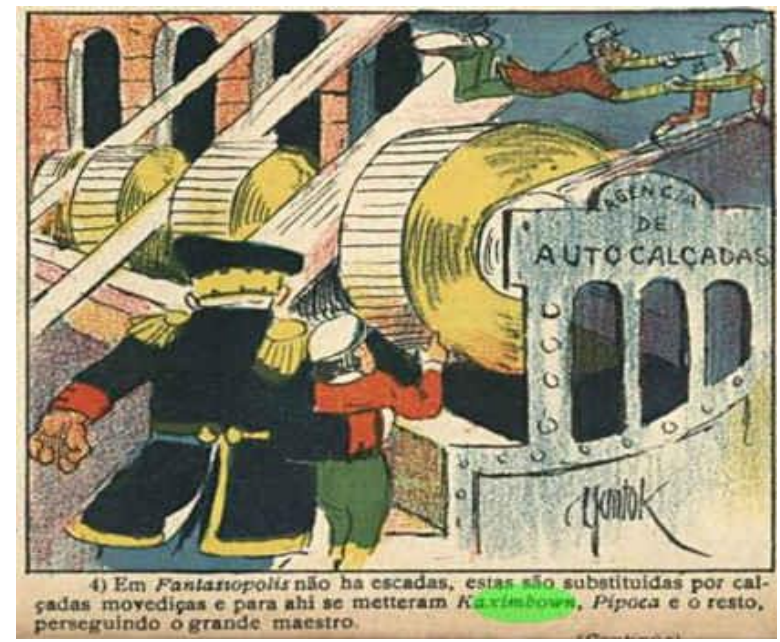

Figura 3. "Aventuras de Kaximbown em Fantasiópolis" (Yantok. O Tico Tico, n. 323, p. 11, 13/12/1911- detalhe). Acervo Hemeroteca Digital da Biblioteca Nacional.

É possível, nessa cidade, usar um "taxilombrigomével" para ir à Estação Central da "Lunatic Railway of Absurdonic Company Extralimited", alusão, talvez, às companhias de trens no Brasil, dominadas pelos ingleses e uma ironia à forte influência da língua e do poderio econômico inglês em nosso país, especialmente nos transportes e no comércio. ${ }^{20}$

As formas de alimentação causam estranhamento e são automatizadas, como no "restaurante Radiogestivo", com um menu variado, com pratos como "costeletas de cupim" e "pirão de baratas". Era só apertar o botão respectivo do prato escolhido, e a comida era servida. 0 caixa também era automático e uma mão mecânica cobrava a dívida. ${ }^{21}$

Em meio a muitas trapalhadas, artefatos como o telefone, o gramofone (nesse lugar a música é usada como instrumento de tortura), o canhão (inventado por Kaximbown para lançar Pistolão às alturas e salvar Pipoca da prisão) ganham destaque no desenrolar da aventura.

Na edição n. 311, a referência à Gazeta de Fantasiópolis é uma forte ironia à imprensa. Os jornalistas aparecem com a cabeça conectada a máquinas e a grandes reservatórios, com placas "Crimes, roubos, erros de gramática", "Atropelos, pesadelos", "casos de fome, suspeita, receitas", "Grande fábrica de assuntos para jornais, movida a vales", "Reservatórios de Mentiras". Essa parece ser mais uma visão da imprensa republicana, de seu papel na nascente indústria cultural e de sua crescente influência na opinião pública, do que de um mundo imaginário. No último quadrinho, a crítica se transforma em metalinguagem, pois, embaixo do braço do sapo jornaleiro, pode-se ver um exemplar de $O$ Tico Tico. Na edição seguinte, Kaximbown, Tonico, Pipoca e Pistolão são entrevistados. O próprio desenhista ri de si mesmo, ao colocar-se entre os repórteres que, para terem boas ideias durante as entrevistas, precisavam de um aparelho especial, o "injetor automático de espírito" (Figura 4).

${ }^{20}$ O Tico-Tico, n. 305, 9/8/1911, p. 14.

${ }^{21}$ Idem, n. 309, 6/9/1911, p. 14. 




Figura 4. "Aventuras de Kaximbown em Fantasiópolis" (Yantok. O Tico-Tico, n. 312, p. 11, 27/9/1911 - detalhe). Acervo Hemeroteca Digital da Biblioteca Nacional.

Nesse universo fantástico, há uma máquina pneumática para cortar cabelos e barbas e outra máquina para restituir cabelos aos carecas. Kaximbown, Pipoca e Pistolão experimentam e ficam com grandes cabelos e barbas, como "dois terríveis anarquistas russos" ${ }^{\prime 22}$. Esse processo de automatização da vida também está presente em outro momento da história, quando, após uma operação motivada por um ferimento, Pipoca é reconstruído por meio da tecnologia existente nas "fábricas de Pipocas e outros ingredientes". ${ }^{23}$

Em uma das muitas confusões enfrentadas, Kaximbown é levado para a Casa de Detenção, condenado a 400 anos de prisão. Lá dentro havia um "irrigador de ar líquido" para evitar "o cólera morbus". Kaximbown tomou o ar como se fosse cerveja, o suficiente para ficar transparente e escapar da prisão, levando consigo os companheiros. ${ }^{24}$

22 O Tico-Tico, n. $318,8 / 11 / 1911$, p. 14 . Yantok reflete e refrata o discurso oficial de criminalização do movimento anarquista assumido pelo governo brasileiro. Sobre o anarquismo na Primeira República, ver: Toledo, Edilene. A trajetória anarquista no Brasil da Primeira República. In: Ferreira, Jorge \& Reis, Daniel Araão. As esquerdas no Brasil: A Formação das Tradições (1889-1945). Rio de Janeiro: Civilização Brasileira, 2007, p. 53-87.

${ }^{23}$ O Tico-Tico, n. 307, 23/8/1911, p. 14.

${ }^{24}$ Idem, n. 320, 22/11/1911, p. 11. 


\section{Polo Norte}

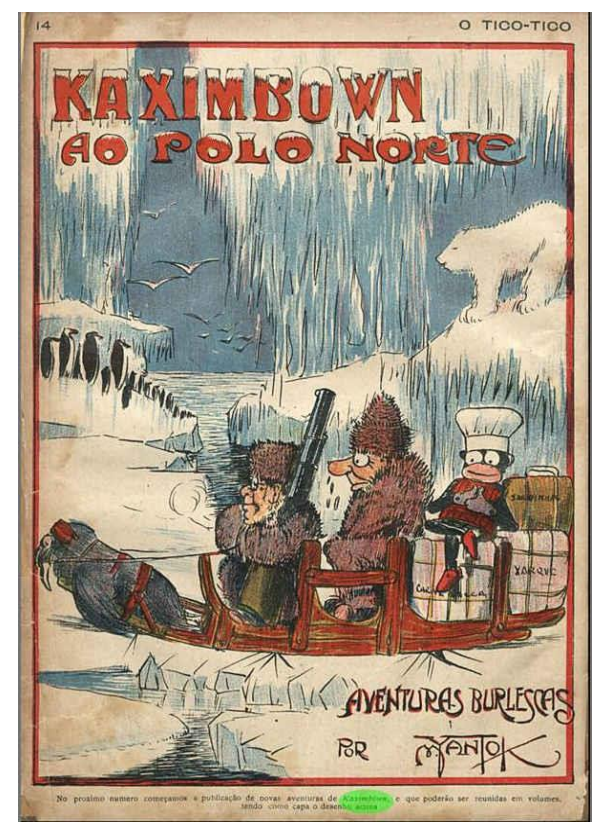

Figura 5. "Kaximbown ao Polo Norte" (Yantok. O Tico-Tico, n. 326, p. 14, 30/1/1912). Acervo Hemeroteca Digital da Biblioteca Nacional.

As aventuras no Polo Norte são apresentadas em um quadro único, na posição vertical da página, como a capa de um livro ou um anúncio, em que a tipografia não apenas informa, mas cria hierarquia de leitura e adapta-se à temática ilustrada. $\mathrm{O}$ título, em vermelho e em caixa alta, nomeia o personagem principal com uma fonte mais rígida e o destino da viagem com uma fonte mais solta e curva, ambas cobertas por neve. Uma letra quase cursiva e ornamentada informa: "Aventuras burlescas, por M Yantok". No primeiro plano vemos um trenó puxado por um leão marinho, com Kaximbown portando uma arma, Pipoca com frio e o nariz pingando, e um macaco/boneco articulado de madeira, com um gorro de cozinheiro, sentado sobre as bagagens, onde se pode ler: "sardinhas", "carne seca", "xarque". Ao fundo, pinguins, um urso polar e aves/pássaros voando, muito gelo completam o ambiente.

O personagem Sábado era uma espécie de boneco/robô preto com pernas e braços articulados e corpo de barrica, cara de macaco, construído e criado por Kaximbown como um filho, algo como um Pinóquio dos trópicos. É possível fazer uma associação com o personagem Sexta-Feira, companheiro de Robinson Crusoé. Sua namorada, Emerenciana, aparece uma única vez, antes da partida, e é desenhada com traços grotescos para definir uma menina negra, seguindo o padrão racial estereotipado e preconceituoso da época. ${ }^{25}$

No decorrer da história, para poder ver a grande variedade de peixes no fundo do mar, entram em um "sino de ar", uma espécie de esfera com uma lanterna, e descem a "quatro mil metros de profundidade". ${ }^{26}$

${ }^{25}$ O Tico-Tico, n. 330, 31/1/1912, p. 20.

${ }^{26}$ O Tico-Tico, n. 333, 21/2/1912, p. 24. 
Durante a expedição, convivem com gigantescos polvos, um deles, inclusive, tornou-se o copeiro do navio, ursos polares, pinguins, um jacaré polar (mais parecido com um dragão), uma baleia, uma foca, um cão marinho (uma serpente com cara de cachorro), atravessam cavernas com aparência de caveiras. O ponto alto da viagem é, sem dúvida, a descoberta do eixo da Terra (Figura 6).



Figura 6. "Kaximbown ao Polo Norte" (Yantok. O Tico-Tico, n. 355, p. 11, 24/7/1912) .Acervo: Hemeroteca Digital da Biblioteca Nacional.

Um quadrinho único, em página inteira mostra um verdadeiro cenário de ficção científica. No interior de uma gruta, à beira de um abismo, Kaximbown "viu um enorme eixo movido à eletricidade, com tantos maquinismos complicados, que o deixaram tonto." Era o eixo da Terra, que se julgava imaginário. Há um grande eixo centralizado em uma ligeira diagonal para a esquerda, muitas engrenagens e roldanas, vários painéis de controle, mostradores ou relógios, como manômetros. As pessoas são representadas em escala bem menor, uniformizadas, controlando as máquinas. A cena é carregada por uma sensação do sublime tecnológico ${ }^{27}$, em que a grandiosidade da engenharia se sobrepõe à capacidade humana. Os balões "Falta um parafuso no Equador", "O vulcão Vesúvio não funciona", "Suspenda o terremoto na Calábria", exemplificam os problemas enfrentados e dão voz e agência aos trabalhadores. $\mathrm{O}$ aviso para não cuspir no chão normatiza o comportamento na "Companhia Elétrica de rotação terrestre".

\footnotetext{
${ }^{27}$ Para uma discussão mais ampla sobre o sublime tecnológico, ver NYE, David E. American Technological Sublime. Cambridge (Mass.): MIT Press, 1996.
} 
Kaximbown tenta descobrir como as máquinas funcionam, mas acaba levando um choque. Ao final da aventura, quando não aguentava mais o frio, jogou-se, seguido pelos companheiros, em uma das caldeiras, a do vulcão Hecla, e junto com a lava foram disparados para longe, e "Foram dar de costados no alto do Pão de Açúcar". 28

Yantok apropria-se do imaginário verniano, mais especificamente de Aventuras do Capitão Hatteras ${ }^{29}$, ao colocar no centro do Polo Norte um vulcão. A reafirmação dessa imagem, desmentida pelos relatos das expedições ao Polo Norte, serve à intenção do caricaturista de ressaltar o domínio humano sobre a natureza, por meio das engrenagens que movimentam, no interior do vulcão, 0 eixo da terra. Mas, esse controle é sempre solapado pelas tresloucadas atitudes de Pipoca e Sábado, ou pela engenhosidade de Kaximbown.

\section{Pandegolândia}

Kaximbown decide ir à terra dos pândegos (pessoas engraçadas, brincalhonas), a Pandegolândia, com Tonico e Pipoca. Sábado vai escondido em um baú. Usam um aeroplano como meio de transporte, uma espécie de trem/bonde alado.

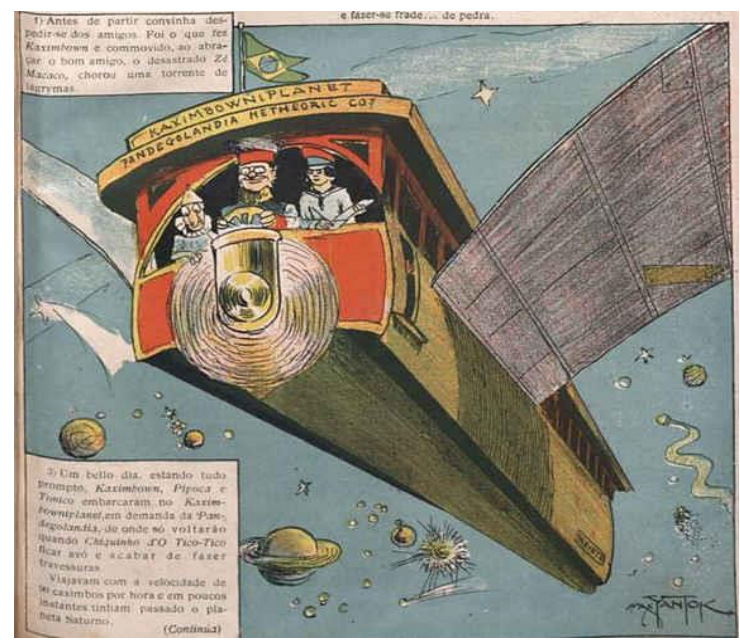

Figura 7. "Aventuras de Kaximbown na Pandegolândia" (Yantok. O Tico-Tico, n. 362, p. 11, 11/9/1912). Acervo Hemeroteca Digital da Biblioteca Nacional.

A diagramação das páginas é mais sofisticada, com maior dinâmica dada pelas diferentes configurações dos quadrinhos, com cenas em destaque

28 O Tico-Tico, n. 358, 14/8/1912, p. 11.

${ }^{29}$ Yantok, nessa história, parece sofrer diferentes influências. Por um lado, a já assinalada admiração por Júlio Verne. Verne publicara em 1886, As Aventuras do Capitão Hatteras, na qual esse herói lidera uma expedição que procurará chegar ao Polo Norte. Ver, Verne, Júlio. As Aventuras do Capitão Hatteras. Rio de Janeiro: Francisco Alves, 1959. Por outro lado, Yantok, pode ter sido influenciado pelo impacto da polêmica "descoberta" do Polo Norte por Robert Leary, em 1909. 
delimitadas por círculos, criando um efeito de $z o o m^{30}$ ou mostrando outro ângulo da narrativa. Esta é a aventura mais nonsense de Yantok, com muitos elementos bizarros, desde os trajes extravagantes e luxuosos, fantasias de palhaços, seres híbridos, objetos animados, objetos usados em funções diferentes daquelas para as quais foram projetados.

A grande metrópole de Pandegolândia era Estapafurdópolis, rica e luxuosa, cuja arquitetura eclética reflete-se em cúpulas, arcos romanos, arcos góticos, flamejantes, mouriscos, pináculos, torres, justapondo estilos dominados por certo orientalismo (Figura 8).



Figura 8. "Aventuras de Kaximbown na Pandegolândia" (Yantok. O Tico-Tico, n. 365, p. 11, 2/10/1912) Acervo Hemeroteca Digital da Biblioteca Nacional.

Os aventureiros passam por muitas situações tumultuadas e até reviravoltas políticas. Quando o rei Pau d'Água ${ }^{31}$ morre de bebedeira, Pipoca é nomeado seu sucessor e um de seus atos é abolir a carestia de vida, garantindo comida de graça para todos.

\section{Planeta Marte}

De Pandegolândia, o grupo resolve partir para Marte, chegando à capital Espalhafatópolis, uma cidade que Ihes pareceu "deslumbrante, monumental, esplendorosa, brilhante, espipoqueante de luzes e maravilhas". Antes de entrar, descobrem que precisam conhecer a moda e os novos costumes, pois o traje a rigor era uma exigência. Kaximbown estuda e faz medições com o compasso em uma espécie de globo marciano, com o mapa do planeta cheio de indicações científicas e descobertas de astrônomos.

Na Figura 5 vê-se em destaque o palácio imperial, guardado por Mico e Tico.

\footnotetext{
${ }^{30}$ Esse tipo de quadrinho é também conhecido como vinheta-flash ou vinheta-relâmpago e cria o efeito de sentido de uma lente, aumentando ou deslocando o ângulo da cena. Ver RAMOS, Paulo. A leitura dos quadrinhos. São Paulo: Contexto, 2009, p. 97.

${ }^{31}$ Gíria da época para a pessoa que bebia muito.
} 


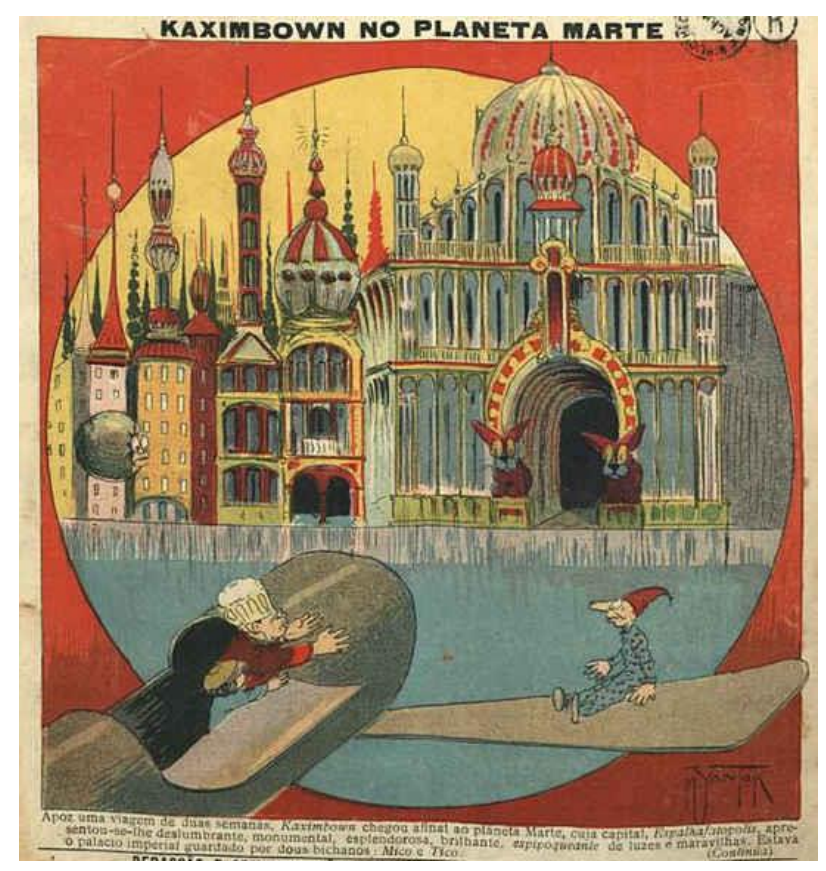

Figura 9. "Kaximbown no Planeta Marte" (Yantok. O Tico-Tico, n. 405, capa, 9/7/1913). Acervo Hemeroteca Digital da Biblioteca Nacional.

O fundo vermelho, reforçando a associação com o planeta Marte, e a paisagem envolvida por um círculo, restando apenas os pináculos e a nave para fora dos limites, ampliam a grandiosidade da arquitetura, uma complexa mistura de elementos bizantinos, islâmicos, futuristas. O fantástico e o exótico remetem à visão romântica de um orientalismo ${ }^{32}$ imaginado.

32 Orientalismo no sentido dado por Edward Said, como uma invenção europeia, constituindo um cenário de romances, seres exóticos, recordações e paisagens inesquecíveis, experiências extraordinárias. Trata-se de um modo de se relacionar com o Oriente que pressupõe o domínio europeu. SAID, E. Orientalismo. São Paulo: Companhia de Bolso, 2007. 


\section{histtórias história}

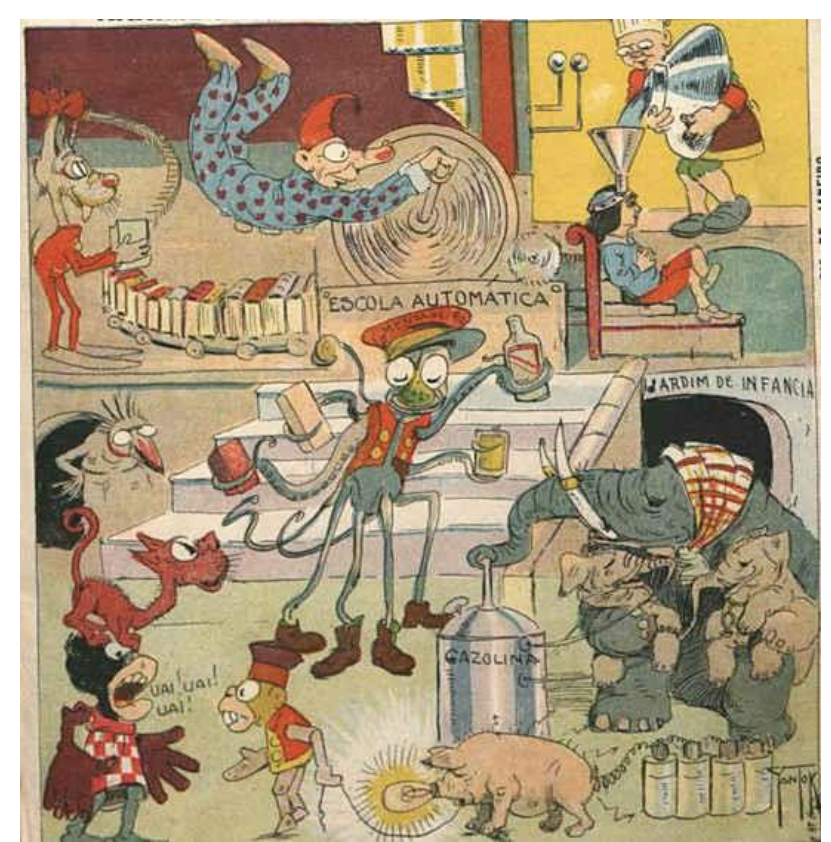

Figura 10. "Kaximbown no Planeta Marte" (Yantok. O Tico-Tico, n. 408, capa, 30/7/1913). Acervo Hemeroteca Digital da Biblioteca Nacional.

Chama a atenção o fato de que o quadrinho destinado a mostrar a praça de Espalhafatópolis (Figura 10) destaca várias cenas simultâneas e procedimentos técnicos, como uma esteira de livros ligadas a uma "escola automática", um menino recebendo um conteúdo líquido por meio de um funil acoplado à cabeça, a entrada de um jardim de infância, um polvo como mensageiro. Há ironias a fontes de energia como a gasolina e a eletricidade. A automatização e mecanização do ensino, do transporte e das comunicações é um tema recorrente não só nas aventuras de Kaximbown, mas em muitas das charges de Yantok.

As críticas aos vários níveis de educação estão presentes nessa história, com destaque para o momento em que o grupo invade a Universidade do Dr. Tudo Sabe, interrompendo os velhos sábios que estavam seriamente pesquisando quando é que se deve comer o repolho (cru, cozido ou podre?).

Os habitantes dessa cidade, como os animais de uma fábula, são descritos como pacatos e pacíficos, em contraste com os turbulentos aventureiros que causam tantas confusões. Entretanto, cansados dos estragos causados pelos forasteiros, tramam um plano para acabar com eles. Kaximbown, Pipoca, Tonico e Sábado, desesperados em fugir do planeta (Figura 11), ao verem uma placa "Estrada de Chumbo para o outro mundo, horário dos trens" e um botão, não tiveram dúvidas em apertá-lo. Vários tiros são disparados automaticamente e todos morrem. 


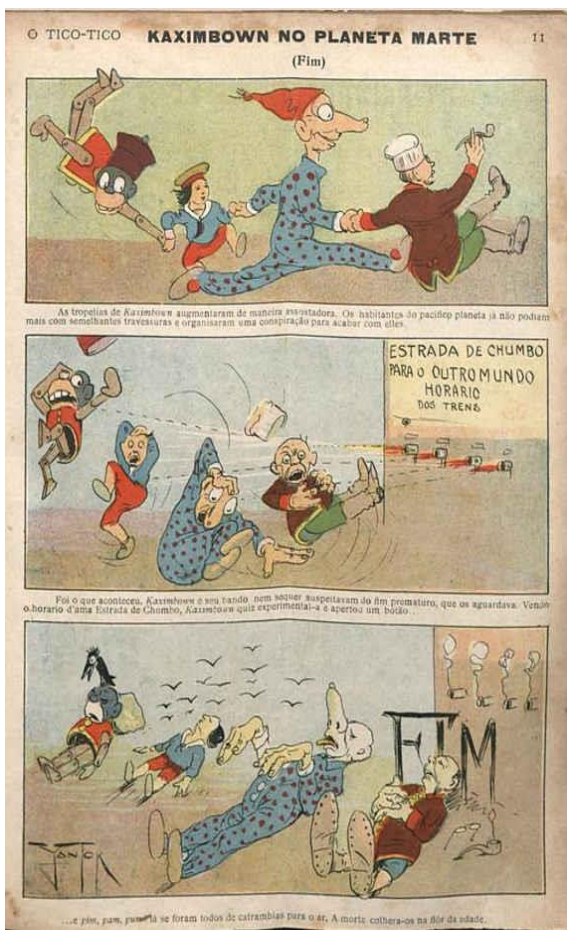

Figura 11. "Kaximbown no Planeta Marte" (Yantok. O Tico-Tico, n. 409, p. 11, 6/7/1913).

.Acervo Hemeroteca Digital da Biblioteca Nacional.

Difícil compreender esse final trágico e inusitado sem ter em mente o belicismo e as tensões às vésperas da Primeira Guerra Mundial.

\section{Considerações finais}

Desde o século XIX a cidade havia se tornado palco e personagem das críticas à sociedade industrial e à exploração do trabalho. Os centros urbanos eram associados a vícios, terror e caos. No Brasil, no início da República, os projetos de reformas urbanas, que procuravam combater a "degeneração social", inspiravam-se nas metrópoles europeias, apontando o progresso e a modernidade como signos de civilização. O fascínio e a desconfiança com a ciência e a tecnologia jogaram para futuras cidades utópicas os sonhos e as promessas das novas invenções.

Nas cidades visitadas por Kaximbown, percebe-se uma crítica bemhumorada ao presente por meio dos elementos utópicos que constroem uma paródia do futuro, onde a arquitetura remete a mundos maravilhosos, edifícios suntuosos, ornamentos variados, e estabelece 0 distanciamento e estranhamento de outros modelos de organização social. Fantasiópolis, Estapafurdópolis, Espalhafatópolis parecem ser expressões de uma releitura bizarra da Belle Époque brasileira, caracterizada pela urbanização e pelo ecletismo arquitetônico financiado pela economia do café.

Nos quadrinhos analisados de Max Yantok, os artefatos tecnológicos e as máquinas são vistos como extensões do corpo, como prolongamento das faculdades humanas. Multiplicam-se máquinas inusitadas, como o "injetor 
automático de espírito", o "besouroplano", o "restaurante radiodigestivo", que são acompanhados por megalópoles de mais de mil andares e seres extraordinários. Yantok, em suas narrativas tecnológicas, parece tomado pela noção de que a nova racionalidade técnica exigiria um novo ser humano. Se há, por um lado, um otimismo acerca do papel da ciência e da tecnologia na construção de um futuro perfeito, por outro lado, as brincadeiras, as cenas de pastelão e a constante violência presentes em suas histórias, operam por meio da sátira e da ironia, inversões e questionamentos, com elementos distópicos no presente e no futuro. O ideal da automatização (da mobilidade e dos transportes, da alimentação, da educação, entre outros) e a eficiência das máquinas são postos em xeque o tempo todo por meio das trapalhadas de Kaximbown e seus companheiros (intrusos, invasores ou desbravadores?), criando deslocamentos constantes de produção de sentido.

Relativiza-se o papel absoluto da ciência e da tecnologia ao enfatizar a agência humana que as produz e as estraga, nas figuras de Kaximbown, Pipoca e Sábado. Ironiza-se o presente por meio das dimensões utópicas, que imaginam um mundo ao avesso, onde a polícia traz segurança, o transporte é eficiente. A crítica é reiterada ao sugerir que a maioria das confusões se dá pelo desconhecimento das regras, pela falta de compreensão dos hábitos e dos costumes dos outros, pelo olhar etnocêntrico que os domina. Yantok também dialoga e reafirma preconceitos de classe ao reproduzir acriticamente desigualdades sociais e assimetrias de poder; preconceitos raciais; preconceitos de gênero, pela notável ausência de personagens femininos em suas narrativas.

Yantok é um inventor de novas cartografias imaginárias, que entrelaçam utopias e distopias, esperanças e temores de um novo mundo que se anuncia, melancolicamente, na modernização brasileira.

\section{Sobre a autora}

Marilda Lopes Pinheiro Queluz possui graduação em História (UFPR) e em Artes (UFPR). Mestrado em História Social (UFPR) e Doutorado em Comunicação e Semiótica (PUC-SP). Professora de História da Arte e História do Design do Departamento Acadêmico de Desenho Industrial e do Programa de PósGraduação em Tecnologia (PPGTE) da UTFPR. E-mail: pqueluz@gmail.com.

Artigo recebido em 23 de novembro de 2015. Aprovado em 01 de junho de 2016. 